\title{
Role of Multi Detector Computed Tomography in Evaluation of Abdominal Trauma
}

\author{
Dr. Mohd Abbas Ilyas, Dr. (Brig.) Kulamani Sahoo, Dr. Pramod Shaha, \\ Dr. Rahul Khetawat, Dr. Gaurav Khairnar \\ Krishna Institute of Medical Sciences, Karad, Maharashtra, India
}

\begin{abstract}
Introduction: Abdominal injury constitutes a significant portion of all blunt and penetrating body injuries. As frequency of intra-abdominal injuries continues to increase worldwide, management in patients with suspected abdominal injury is getting more complex. CT is an important and fast technique which gives rapid information on the type of abdominal injury and helps in management of the patient. Aims and Objectives: Determine the usefulness of MDCT findings in deciding the management of patients with blunt abdominal trauma and To diagnose and grade various abdominal injuries in trauma using MDCT. Materials and Methods: This Prospective Study is carried out in patients admitted to our hospital with history of BAT during the period of September 2014 to September 2016. A total of 50 patients with BAT who underwent CT examination were included using SOMATOM EMOTION 16 slice MDCT. CT findings were compared with surgical findings in operated cases and rest were compared with the clinical outcome. Results: Among the 50 cases studied, 46 had positive CT findings of abdominal trauma, out of which 25 patients underwent surgery and the remaining were managed conservatively. In this study, the commonest organs affected were spleen and liver accounting for $40 \%$ and 20\% respectively. Conclusion: $C T$ is an important imaging technique for diagnosis of organ injuries in patients with abdominal trauma. It helps in grading of the type of injury and deciding the management of patient. It is a highly sensitive imaging modality for the diagnosis of abdominal injuries.
\end{abstract}

Keywords: blunt abdominal trauma (BAT), multidetector computed tomography

\section{Introduction}

Blunt abdominal trauma is a leading cause of morbidity and mortality among all age groups and occurs mostly with road traffic accidents, with falls (mainly on the work site), and violence $^{1}$ accounting for the other causes. Road traffic crashes kill 1.2 million people annually around the world (3242 people a day), $90 \%$ of these deaths are in low or middle income countries. It is predicted to become the third largest contributor to the global burden of disease by $2020^{2}$.

Many of these patients have multisystem injuries resulting from high velocity mechanism and identification of serious intra-abdominal pathology is often challenging.

The presence of associated injuries may mask clinical manifestations or divert the attention away from potentially life-threatening intra-abdominal bleeding injuries may not manifest during the initial period ${ }^{3}$.

Imaging plays a critical role in the evaluation of patients with blunt abdominal trauma. CT as the sole modality, enables evaluation of other associated injuries in addition to global evaluation of abdominal trauma. In blunt injuries, the solid organs are mostly involved, followed by the hollow organs ${ }^{4}$.

CT has proved to be a highly sensitive and specific method for the detection of abdominal injury, and is the method of choice for the initial evaluation of patients who are hemodynamically stable ${ }^{5}$.

MDCT allows for complete scanning in a single breath-hold, and faster scanning speeds and narrow collimation, increase contrast opacification in the abdominal vessels, as well as in parenchymal organs. This improves identification of organ injury and additionally, sites of active arterial bleeding.
Breath holding may not be possible in trauma CT, and the speed of MDCT scanning further reduces breathing artefact $^{6,7}$

The accuracy of CT in hemodynamically stable blunt trauma patients has been well established.

The more recent development of MDCT technology has further enhanced the role of CT in the evaluation of blunt abdominal trauma.

\section{Aims and Objectives}

1) Determine the usefulness of MDCT findings in deciding the management of patients with blunt abdominal trauma (BAT).

2) To diagnose and grade various abdominal injuries in trauma using MDCT.

3) Following the radiological imaging the patients were followed up for their management and outcome.

\section{Materials and Methods}

This prospective study was done on all patients referred to Krishna Hospital, Karad for CECT Abdomen \& Pelvis with a history of Blunt Abdominal Trauma (BAT) and were hemodynamically stable. This study was conducted for a period of 2 years from September 2014 to September 2016 with a sample size of 50 patients, after taking the institutional ethical clearance.

\section{Inclusion Criteria}

- Hemodynamically stable patient.

- Patients with history of trauma. 


\section{International Journal of Science and Research (IJSR) \\ ISSN (Online): 2319-7064}

Index Copernicus Value (2015): 78.96 | Impact Factor (2015): 6.391

Exclusion Criteria

- All hemodynamically unstable patients.

Informed consent was obtained from the patients in English or regional language.

\section{Method of Study}

All CECT scans were done on SOMATOM EMOTION 16 slice MDCT with $130 \mathrm{KVp}$ and $120 \mathrm{~mA}$ (Care Dose 120 $\mathrm{mA}$ ) with $5 \mathrm{~mm}$ thickness and retro reconstruction of 1.5 $\mathrm{mm}$ thickness with a rotation time of $0.6 \mathrm{~s}$, a maximum table speed of $1.2 \mathrm{~mm} / \mathrm{s}$, and with matrix size of $512 \times 512$; pitch of 1.25; FOV 300-400mm; Collimation: $1.2 \mathrm{~mm}$; Time for scan: 11 seconds.

Bolus tracking method was used and sections are taken from bilateral domes of diaphragm to pubic symphysis. Arterial phase is taken at 25-30 sec; Portal phase at 40-45 sec; Venous phase at 70-80 sec and Delayed at $180 \mathrm{sec}$ from the start of injection. $100 \mathrm{ml}$ of $35 \mathrm{~g}$ of non-ionic iodinated contrast was injected in adults using pressure injector at the rate of $3-4 \mathrm{ml} / \mathrm{sec}$ through an 18 to 20 gauge cannula located in a large peripheral vein. In children a dose of $1.2 \mathrm{ml} / \mathrm{kg}$ of $300 \mathrm{mg} / \mathrm{ml}$ non-ionic iodinated contrast was injected at a rate of $2-2.5 \mathrm{ml} / \mathrm{sec}$ and Arterial phase is taken at $20 \mathrm{sec}$; Portal phase at $35 \mathrm{sec}$; Venous phase at $60 \mathrm{sec}$ and Delayed at 180 sec from the start of injection \& for genitourinary trauma a second delayed phase is taken at $10 \mathrm{~min}$.

Acquisition of arterial phase, venous phase and delayed images were taken from the bilateral domes of diaphragm to inferior margin of pubic symphysis and portal phase images from bilateral domes of diaphragm to inferior margin of liver. Following the radiological imaging the patients were followed up for their management and outcome.

Multi-planar reconstructions (MPRs) at $0.6 \mathrm{~mm}$ thickness in coronal and sagittal planes are routinely obtained to evaluate the abdominal structures.

Maximum-intensity projections (MIPs) and volumerendering (VR) reconstructions are performed in cases of vascular lesions.

Individual organ injuries were graded according to the OIS system and injury severity grades given by Moore E.E. et $\mathrm{al}^{8}$ were followed.

\section{Statistical Methods}

Descriptive and inferential statistical analysis as mean, SD, percentage, proportions etc. has been carried out in the present study. Comparison of parameter difference was done by applying $\mathrm{Z}$ test of difference between two samples at $5 \%$ and $1 \%$ level of significance.

\section{Statistical Software}

The Statistical software namely SYSTAT version 12 was applied for the analysis of the data and Microsoft word and Excel have been used to generate graphs, tables etc.

\section{Observation \& Results}

\section{a) Age Distribution}

Table 1: Percent ratio of various groups involved in BAT

\begin{tabular}{|c|c|c|}
\hline Age in years & No. of cases & Percentage (\%) \\
\hline$<10$ & 4 & $8 \%$ \\
\hline $11-20$ & 10 & $20 \%$ \\
\hline $21-30$ & 14 & $28 \%$ \\
\hline $31-40$ & 7 & $14 \%$ \\
\hline $41-50$ & 6 & $12 \%$ \\
\hline $51-60$ & 4 & $8 \%$ \\
\hline $61-70$ & 3 & $6 \%$ \\
\hline$>70$ & 2 & $4 \%$ \\
\hline Total & 50 & $100 \%$ \\
\hline
\end{tabular}

b) Sex Distribution of Patients with Abdominal Trauma

Table 2: Sex distribution involved in BAT

\begin{tabular}{|c|c|c|}
\hline Sex & No. of cases & Percentage (\%) \\
\hline Male & 44 & $88 \%$ \\
\hline Female & 6 & $12 \%$ \\
\hline Total & 50 & $100 \%$ \\
\hline
\end{tabular}

c) Mode of Injury

Table 3: Different mode of injury causing BAT

\begin{tabular}{|c|c|c|}
\hline Mode of injury & No. of cases & Percentage (\%) \\
\hline Road Traffic Accident & 42 & $84 \%$ \\
\hline Fall from Height & 7 & $14 \%$ \\
\hline Assault & 1 & $2 \%$ \\
\hline Total & 50 & $100 \%$ \\
\hline
\end{tabular}

By applying $\mathrm{Z}$ test of difference between two sample proportions the proportion of mode of injury RTA is more significant than other mode of injury $(\mathrm{p}<0.05)$

\section{d) Organ Involvement}

Table 4: Different organs involved in BAT

\begin{tabular}{|c|c|c|}
\hline Organs involved & No. of cases & Percentage (\%) \\
\hline Liver & 10 & $20 \%$ \\
\hline Spleen & 20 & $40 \%$ \\
\hline Kidney & 6 & $12 \%$ \\
\hline Bowel & 3 & $6 \%$ \\
\hline Mesentery & 6 & $12 \%$ \\
\hline Stomach & 1 & $2 \%$ \\
\hline None & 4 & $8 \%$ \\
\hline Total & 50 & $100 \%$ \\
\hline
\end{tabular}

By applying $\mathrm{Z}$ test of difference between two sample proportions the proportion of organs spleen, and liver is significantly higher than other organs involved $(\mathrm{p}<0.05)$

\section{e) Intra-Operative Correlation of Grade of Organ Injury}

Table 5: Intraoperative correlation of grade of organ injury

\begin{tabular}{|c|c|c|}
\hline & No. of cases & Percentage (\%) \\
\hline Correlating & 24 & $96 \%$ \\
\hline Not correlating & 1 & $04 \%$ \\
\hline Total & 25 & $100 \%$ \\
\hline
\end{tabular}




\section{International Journal of Science and Research (IJSR) \\ ISSN (Online): 2319-7064 \\ Index Copernicus Value (2015): 78.96 | Impact Factor (2015): 6.391}

By applying $Z$ test of difference between two sample proportions the proportion of correlation of grade of organ injury is significantly exits $(\mathrm{p}<0.05)$

\section{f) Grades of Injury}

Table 6: Different grades of injury found in BAT

\begin{tabular}{|c|c|c|}
\hline Grades of Injury & No. of cases & Percentage (\%) \\
\hline Grade I & 3 & $6 \%$ \\
\hline Grade II & 10 & $20 \%$ \\
\hline Grade III & 13 & $26 \%$ \\
\hline Grade IV & 7 & $14 \%$ \\
\hline Grade V & 4 & $8 \%$ \\
\hline Gastric perforation & 1 & $2 \%$ \\
\hline Mesenteric Infiltration & 6 & $12 \%$ \\
\hline Shock Bowel & 1 & $2 \%$ \\
\hline Colon injury & 1 & $2 \%$ \\
\hline NA & 4 & $8 \%$ \\
\hline Total & 50 & $100 \%$ \\
\hline
\end{tabular}

By applying $Z$ test of difference between two sample proportions the proportion of grades of injury i.e. grade III and grade II is significantly higher than other grades of injury $(\mathrm{p}<0.05)$

\section{g) Mode of Treatment}

Table 7: Mode of treatment chosen following results of CECT findings.

\begin{tabular}{|c|c|c|}
\hline Mode of treatment & No. of cases & Percentage (\%) \\
\hline Conservative & 25 & $50 \%$ \\
\hline Surgical & 25 & $50 \%$ \\
\hline Total & 50 & $100 \%$ \\
\hline
\end{tabular}

\section{Discussion}

Among the 50 cases studied, 25 had undergone for surgical management and 25 were managed conservatively, CT findings correlated with the operative finding in 24 out of 25 patients. However CT finding did not correlate with intraoperative finding in 1 patient.

In this study, the most common organs affected in abdominal trauma were spleen and liver accounting for $40 \%$ and $20 \%$ each respectively, followed by the kidneys $(12 \%)$, Mesentery (12\%), Bowel (6\%), Stomach (2\%). Hemoperitoneum was observed in 25 patients accounting for $50 \%$.

This study has discussed the CT features of abdominal trauma.

These corroborate well with findings/conclusion highlighted by following authors.

In a study by Michael Federle et $\mathrm{al}^{9}$ :

100 cases of abdominal trauma were studied and there was maximum incidence of trauma in age group 21-30 years, which was $35 \%$, followed by age group 11-20 years.

In our study maximum incidence of trauma was seen in age group 21-30 years which was 30\%, followed by age group
$11-20$ years $(20 \%)$.

Younger group of population are more prone for RTA and forms a major role in Blunt abdominal trauma and our findings are similar to the previous study done in literature.

The male: female ratio was 13:7.

In our study male: female ratio was 22:3 suggesting males are more prone to injuries than females.

Male population are most commonly involved in outdoor activities than females making them more prone for blunt abdominal trauma.

Siddique $\mathrm{M} \mathrm{A} \mathrm{B}$ et $\mathrm{al}^{10}$ studied 50 patients of abdominal trauma and concludes stab injuries in 21 patients as leading cause of abdominal trauma followed by motor accidents in 12 patients, assault in 7 patients and fall from height in 4 patients and other causes in 6 patients. In his study vehicular accidents are the major cause of blunt abdominal trauma.

In my study, road traffic accidents (42 out of 50 cases) constituted majority of the cases, followed by fall from height with 7 of 50 patients and 1 patient had history of assault.

As the institution is in close proximity to the national highway, fast moving traffic is present all the time so in our study most common mode of injury is RTA.

In our study there were maximum of grade III injuries ( $26 \%$ ) followed by grade II (20\%), grade IV ( $14 \%)$, grade V ( $8 \%$ ) and grade I ( $6 \%)$.

The reason for grade III, grade II and grade IV injuries being more common can be due to more number of cases belonging to major road traffic accidents and fall from height and as our institution being major referral centre for emergency cases because of its tertiary setup and close proximity to the national highway.

Fang JF et $\mathrm{al}^{11}$ concluded that unstable hemodynamic status should not be a contraindication for a MDCT examination if the facility is readily available, the protocol is well designed, and the patient is well prepared.

My study included all patients who were hemodynamically stable, all unstable patients were referred to the emergency department or to the operating room.

If patients who are hemodynamically unstable underwent CECT examination with non-ionic contrast material there are chances of the patient to go under cardiogenic shock or cardiac arrest due to decrease systemic cardiac output as a result of pump failure. There is contrast material layering in the inferior vena cava which is a marker of imminent cardiogenic shock \&has been reported in one case report in English literature.

Laal Met $\mathrm{al}^{12}$ studied 16,573 patients out of which 106 patients had renal injuries. Out of these 106 cases majority of cases belonged to gradeI constituting $62.3 \%$ of cases followed by grade II and grade III with incidence of $13.2 \%$ 


\section{International Journal of Science and Research (IJSR) \\ ISSN (Online): 2319-7064}

Index Copernicus Value (2015): 78.96 | Impact Factor (2015): 6.391

\& $9.4 \%$ respectively. Grade IV and grade $\mathrm{V}$ was diagnosed in 8 cases each out of 106 cases with incidence of $7.5 \%$ each.

In my study of renal injuries of 6 patients, grade IV and grade III constituted $50 \%$ each.

As the institution is closer to the highway, higher grades of injury are more common in our study.

Clinical signs and symptoms have been identified that are associated with risk of intra-abdominal injury. They include gross hematuria, local abdominal tenderness, abdominal distension, guarding and rigidity, fall in BP \& lower rib fractures.

Biomedical parameters such as raised serum amylase may also be indicative of specific injury. In this study CT has proved very useful in characterization and grading of injury.

The categorization of injuries of the solid viscera on CT has been well documented in literature. The CT features of our study corroborates with the literature.

Khan JS et al $^{13}$ studied 100 cases of abdominal trauma and most of the liver injuries fell under grade I injuries (42.8\%) followed by grade II and grade III injuries (22.85\%).

In our study of 10 Liver injuries, 6 patients presented with grade II constituting $60 \%$, followed by grade III (30\%) and grade I $(10 \%)$

Liver is the largest soft tissue internal organ of the body, higher grade injuries are less common so we have lower grade injuries which is commonest.

CT assessment of grading of liver trauma was correlated with respect to their management protocol. Out of 10 cases, 4 cases were managed surgically owing to their hemodynamic status and rest 6 cases were treated conservatively.

Anderson W S et $\mathrm{al}^{14}$ studied 68 patients of splenic trauma out of which 47 patients underwent computed tomography for examination of abdominal injuries. Out of these 47 cases majority of cases belonged to grade II constituting $45 \%$ of cases followed by grade III and grade IV with incidence of $21 \%$ \& 19\% respectively. Grade I and grade V was diagnosed in 6 and 1 case respectively out of 47 cases with incidence of $13 \%$ and $9 \%$ each.

In our study of 20 splenic injuries, 6 patients presented with grade III constituting $30 \%$, followed by grade II, grade IV \& grade $\mathrm{V}$ constituting $40 \%$ each respectively.

Our study differ from the above mentioned study in literature, as our institution is in close proximity of the highway \& RTA is the commonest mode of injury, higher grades injuries contributes to the splenic injuries.

CT grading of splenic trauma correlated with intra-operative grading in 9 out of 20 patients.

\section{In a study by Brofman $\mathrm{N}$ et $\mathbf{a l}^{\mathbf{1 5}}$}

1) Studied 22 patients with less specific bowel injuries out of which 12 patients had small bowel injury and 21 with large bowel injury and 4 had bowel thickening. Diffuse small bowel wall thickening is atypical for contusion and may represent bowel edema secondary to systemic volume overload or to hypoperfusion complex (aka shock bowel).

In our study of 3 bowel injuries, 1 patient's finding did shock bowel constitute $33.33 \%$.

The successful management of bowel injuries requires a multi-modality approach combining CT findings with serial assessment of the clinical status of the patient. As 1 of our patient had a non-specific sign of bowel injury (shock bowel) \& the patient was hemodynamically stable so was managed conservatively \& the finding could not be corelated intra-operatively.

2 cases of bowel injuries had intra operative management out of which 1 patient presented with colonic injury and in 1 case of jejunal perforation but no specific finding was seen on CT. The reason for under diagnosis in these cases was due to hemoperitoneum which made it difficult to interpret on $\mathrm{CT}$.

There were only 3 cases (less no. of cases) of bowel injury in the study and hence the role of CT in management of these injuries cannot be inferred from the present study. It is not statically significant.

2) Studied 54 patients with mesenteric injuries out of which 37 patients showed haziness and fat stranding (mesenteric infiltration) in the mesentery may indicate mesenteric injury with or without bowel wall injury.

In our study of 6 cases of mesenteric injuries all patients had mesenteric infiltration as finding which is a nonspecific sign but co-related with mesenteric tear which was found intra operatively.

As mesenteric infiltration is a non-specific finding but should also be considered as all our patient's findings with this non-specific sign turned out to have mesenteric tear intra-operatively.

There were only 6 cases (less no. of cases) of mesenteric injury in the study and hence the role of CT in management of these injuries cannot be inferred from the present study. It is not statically significant.

\section{Conclusion}

From the study we concluded the following:-

The challenge in imaging abdominal trauma is to accurately identify injuries that require early exploration and at the same time avoid unnecessary operative intervention in cases that can be managed conservatively.

Most of our cases, $84 \%$ (42 out of 50) of blunt injury to abdomen were secondary to motor vehicle accidents. Majority of the patients (56\%) were in the age group of $<30$ 


\section{International Journal of Science and Research (IJSR) ISSN (Online): 2319-7064 \\ Index Copernicus Value (2015): 78.96 | Impact Factor (2015): 6.391}

years, representing the younger generation who make a major contribution to society.

Solid organs are more prone to abdominal injuries than hollow organs.

Spleen was the most commonly injured organ in this study, followed by liver and kidney. In this study, we could detect only $66.6 \%$ of bowel and $100 \%$ of mesenteric injuries. CT scan findings in bowel and mesenteric injuries can be subtle and non-specific. Surgical exploration should be considered in patients with more than one suspicious finding for bowel or mesenteric injury on CT scan. operative grading with $\mathrm{p}$-value $<0.05$ and hence, is a good and reliable modality to grade intra-abdominal organ injury grading pre-operatively.

Computed tomography is very good modality to identify and grade different types of abdominal injuries. With an overall sensitivity of $94.67 \%$ \& positive predictive value of $79.46 \%$ in this study, it is concluded that CT is a diagnostic modality in the diagnosis and management of blunt abdominal trauma.

\section{Images of Cases}

Computed tomography grading correlated well with intra-

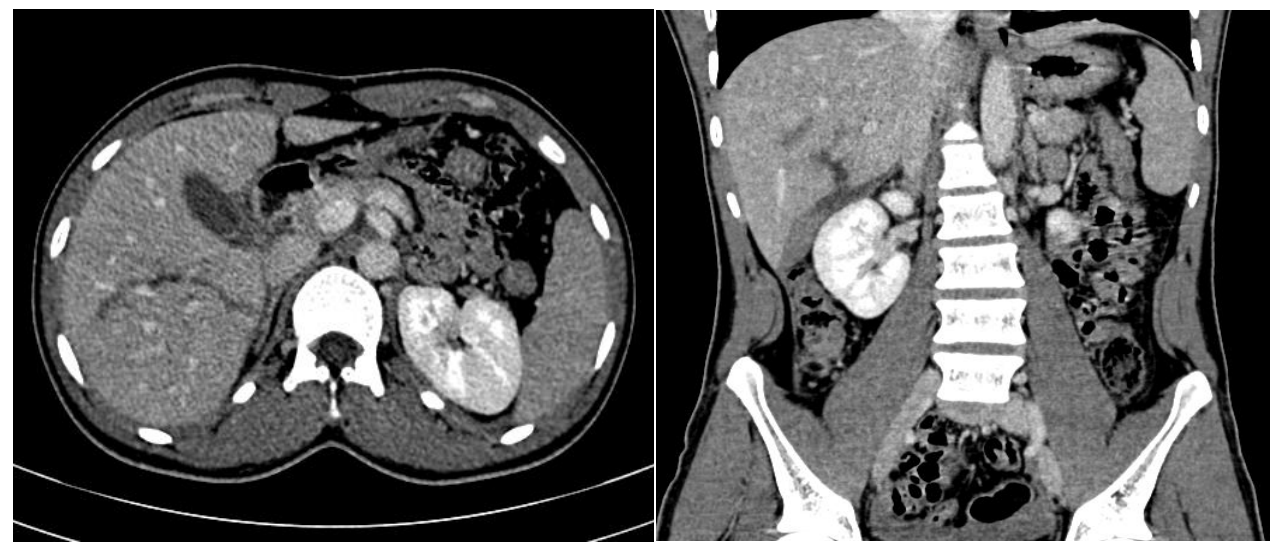

Figure 1: Grade II liver injury

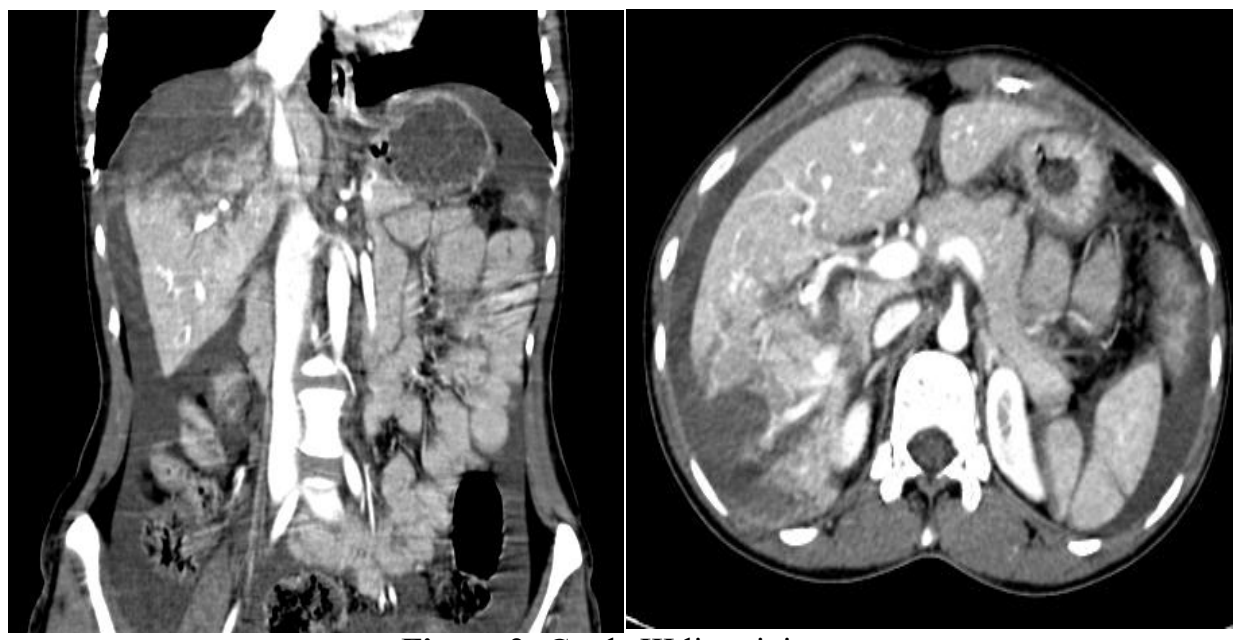

Figure 2: Grade III liver injury 
International Journal of Science and Research (IJSR)

ISSN (Online): 2319-7064

Index Copernicus Value (2015): 78.96 | Impact Factor (2015): 6.391

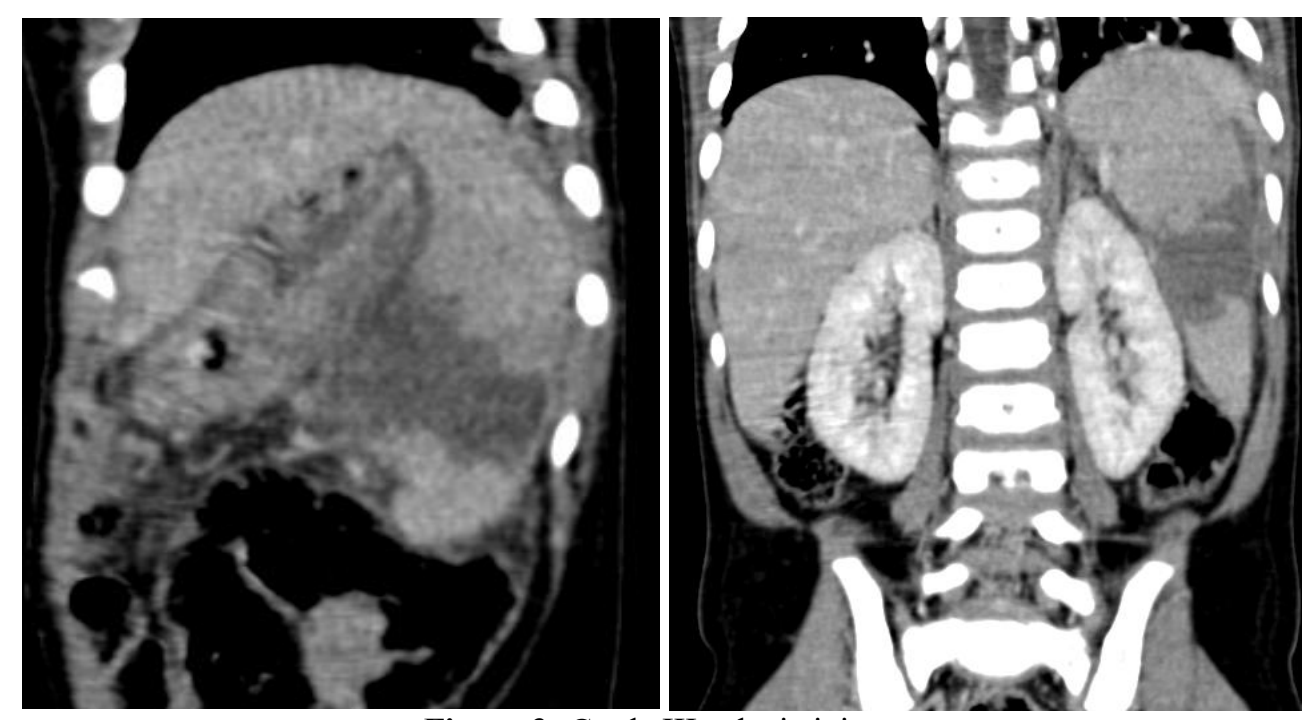

Figure 3: Grade III splenic injury

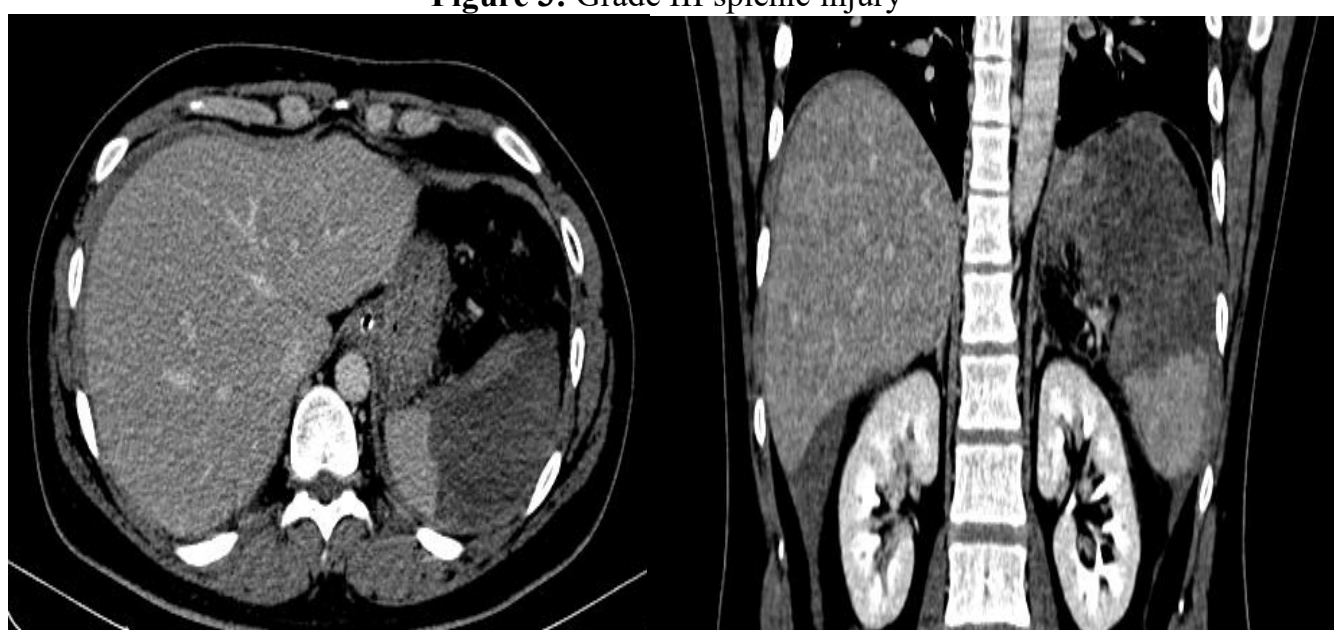

Figure 4: Grade V splenic injury

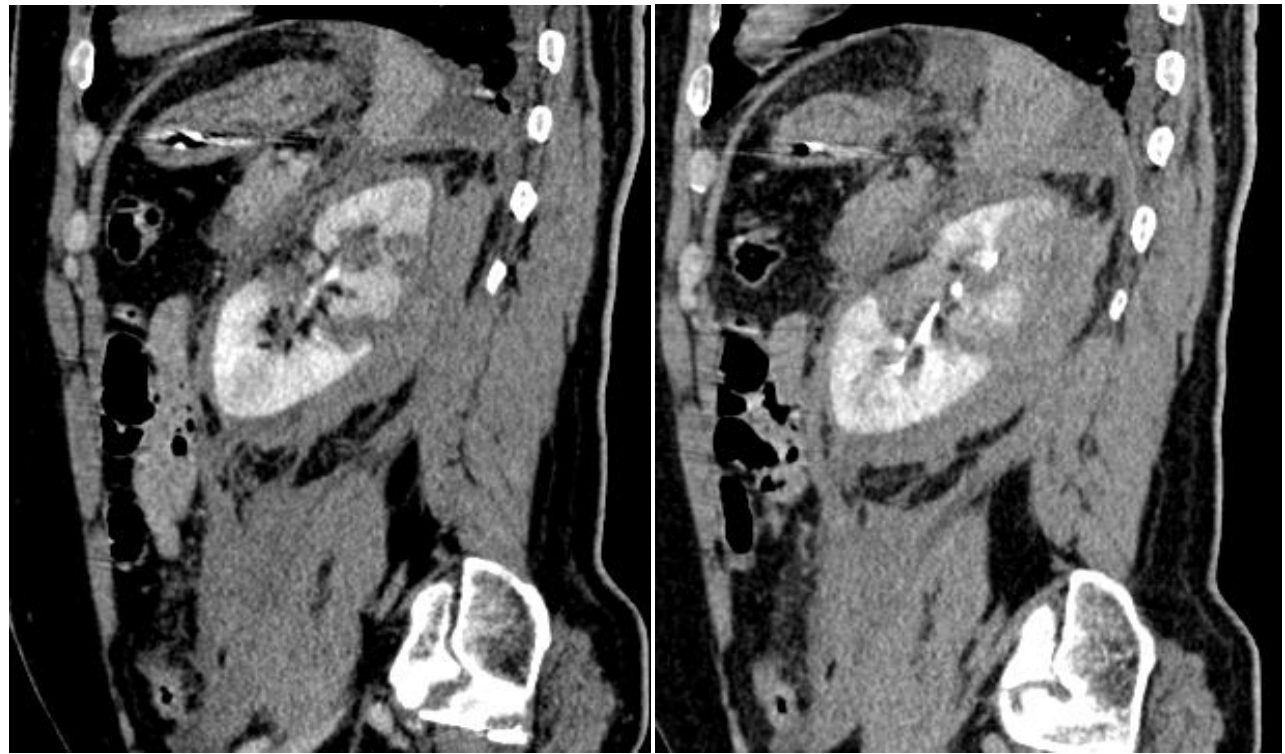

Figure 5: Grade IV renal injury

Volume 6 Issue 1, January 2017

www.ijsr.net 


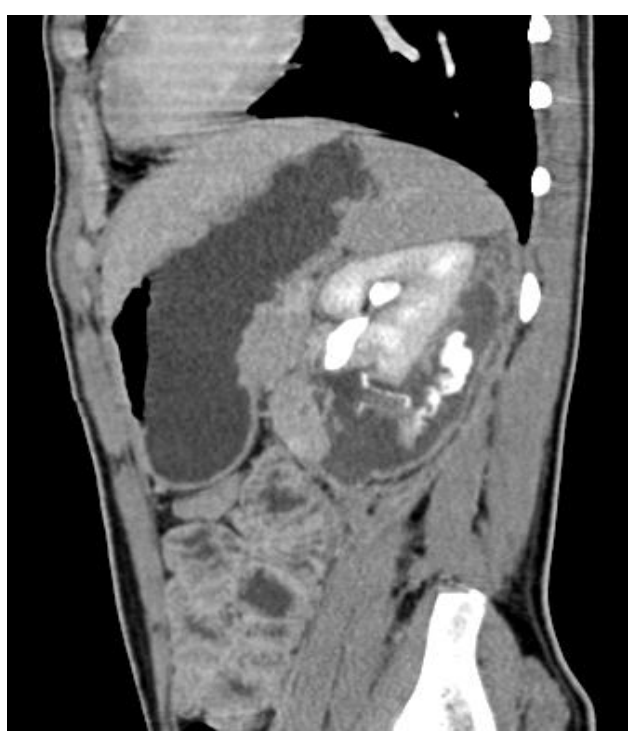

Figure 6: Grade IV renal injury

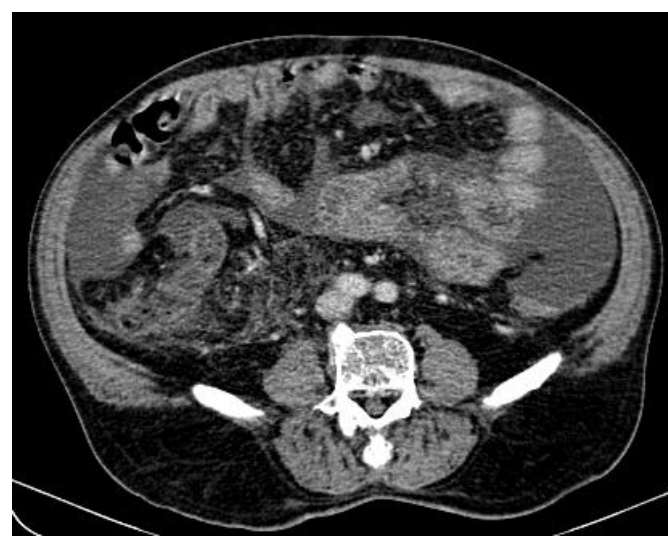

Figure 7: Mesenteric Infiltration

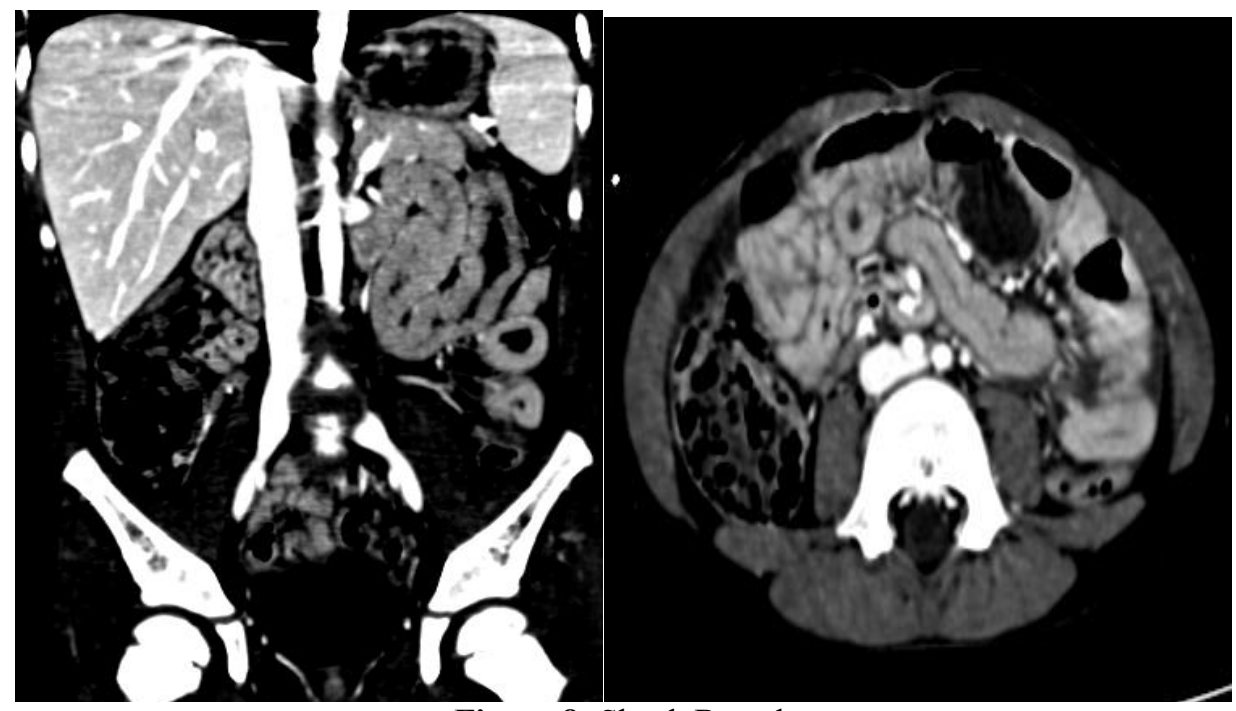

Figure 8: Shock Bowel

Volume 6 Issue 1, January 2017 www.ijsr.net 
International Journal of Science and Research (IJSR)

ISSN (Online): 2319-7064

Index Copernicus Value (2015): 78.96 | Impact Factor (2015): 6.391

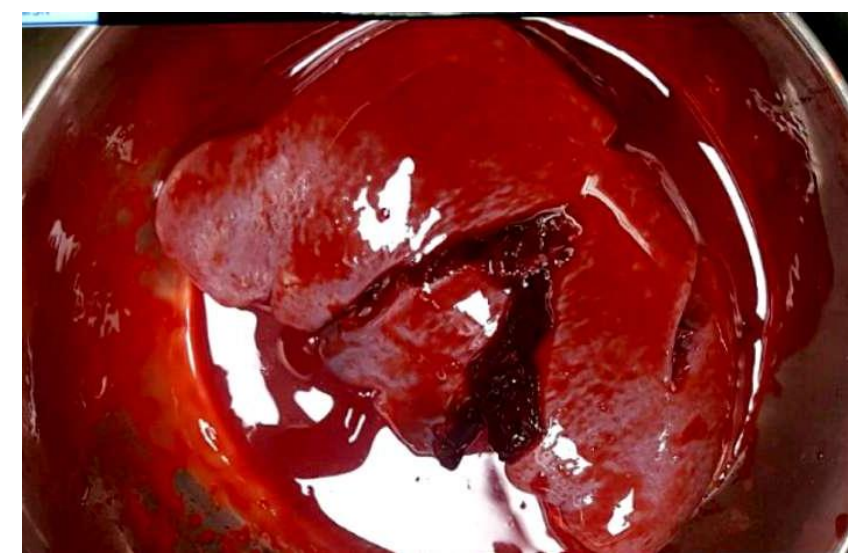

Figure 9: Gross specimen of splenic injury

\section{References}

[1] C. Keith Stone, Roger L. Humphries. Current diagnosis \& treatment: Emergency Medicine, 2007 6th Edition: chapter 25 .

[2] www.aast.org/trauma-facts

[3] Joseph A Salomone III, Jeffrey P Salomone. Abdominal Trauma, Blunt.

http://emedicine.medscape.com/article/821995overview

[4] Eric L Legome, MD; Samuel M Keim, MD, MS ; Abdominal Trauma,

Blunt

http://emedicine.medscape.com/article/1980980overview\#a4

[5] Radhiana Hassan1, 2, AzianAbd. Aziz1; CT imaging of injuries from Blunt Abdominal Trauma: A Pictorial Essay, Malaysian J Med Sci 2010; 17(2): 29-3

[6] Novelline RA, Rhea JT, Bell T. Helical CT of abdominal trauma. RadiolClin North Am 1999;37:591612, vi-vii.

[7] Weishaupt D, Grozaj AM, Willmann JK, et al. Traumatic injuries: imaging of abdominal and pelvic injuries. EurRadiol 2002;12:1295-1311.

[8] Moore EE, Cogbill TH, Malangoni M, Jurkovich GJ, Champion HR. Scaling system for organ specific injuries.

www.aast.org/pdf/library/AAST\%20Injury\%20Tables. pdf.

[9] Federle MP, Courcoulas AP, Powell M, et al : Blunt splenic injury in adults: Clinicaland CT criteria for management, with emphasis on active extravasation. Radiology1998; 206:137-142.

[10] Siddique M A B, Rahman M K, Hannan A B M A Study on Abdominal Injury: AnAnalysis of 50 Cases. TAJ 2004; 17(2): 84-88

[11]Fang JF, Wong YC, Lin BC, Hsu YP, Chen MF. Usefulness of Multidetector Computed Tomography for the Initial Assessment of Blunt Abdominal Trauma Patients : World J Surg 2006;30(2):176-82.

[12]Laal M,Khodadadi F, Zarei M.R: Renal Trauma Management in 8 Cities of Iran.ActaMedicaIranica, 2009; Vol. 47, No.1.

[13] Khan JS, Iqbal N, Gardezi JR Pattern of visceral injuries following blunt abdominaltrauma in motor vehicular accidents. J Coll Physicians Surg Pak. 2006;16(10):645-7.

[14] Anderson et al Blunt Splenic Trauma: Delayed-Phase
CT for Differentiation ofActiveHemorrhage from Contained Vascular Injury in Patients. Radiology: 2007, Volume243: Number 1.

[15]Nicole Brofman, Mostafa Atri, Dip Epid John M. Hanson, Leonard Grinblat, TalatChughtai, Fred Brenneman, Evaluation of Boweland Mesenteric BluntTrauma with Multi-detector CT:RadioGraphics 2006;26:1119-1131. 